\title{
Current and future management of NK/T-cell lymphoma based on clinical trials
}

\author{
Motoko Yamaguchi
}

Received: 21 August 2012/Revised: 22 September 2012/ Accepted: 24 September 2012/Published online: 17 October 2012

(C) The Japanese Society of Hematology 2012

\begin{abstract}
Recently reported results of well-designed prospective clinical trials for extranodal NK/T-cell lymphoma, nasal type (ENKL) have rapidly changed the management of ENKL. This review will focus on the evidence obtained from prospective clinical trials for ENKL and discuss the most highly recommended current management and future directions for the better management of ENKL. For patients with nasal NK/T-cell lymphoma of stage IE or contiguous stage IIE with cervical node involvement, concurrent chemoradiotherapy with radiotherapy (RT) and a two-thirds dose of DeVIC chemotherapy is recommended as a first-line treatment. To obtain the expected clinical outcome, performing RT following the same procedure as that reported is important. For the other patients with newly diagnosed ENKL, SMILE chemotherapy is recommended as an induction therapy. The Epstein-Barr virus DNA load in peripheral blood is useful for both prognostication and monitoring during the follow-up after treatment. Other L-asparaginasecontaining chemotherapies and chemotherapies containing non-multidrug resistance-related agents and etoposide are good options for elderly patients or patients with impaired organ function. As in the cases of other aggressive lymphomas, prospective clinical trials with adequate statistical considerations should be conducted to improve the prognosis of patients with ENKL.
\end{abstract}

Keywords Lymphoma · NK cell · Radiotherapy · Chemotherapy · Prospective clinical trial

M. Yamaguchi $(\bowtie)$

Department of Hematology and Oncology,

Mie University Graduate School of Medicine,

2-174 Edobashi, Tsu, Mie 514-8507, Japan

e-mail:waniwani@clin.medic.mie-u.ac.jp

\section{Introduction}

Extranodal natural killer (NK)/T-cell lymphoma (NKTCL), nasal type (ENKL) is a predominantly extranodal lymphoma associated with Epstein-Barr virus (EBV) [1, 2]. ENKL is much more common in Asia and Latin America than in the USA and Europe [3, 4]. Its frequency relative to that of all lymphomas is approximately 3-10\% in East Asia, but $<1 \%$ in western countries. Recently, the results of well-designed prospective clinical trials for this rare lymphoma have been reported, resulting in the rapid evolution of ENKL management.

Several comprehensive reviews on the pathophysiology, diagnosis, clinical features, risk stratification, and prognosis of ENKL have already been published [5-9]. This review will focus on the evidence from prospective clinical trials for ENKL and discuss the most recommended management at present and future directions for the better management of ENKL.

\section{Barriers against conducting well-designed prospective clinical trials for ENKL}

General factors in the clinical trials for ENKL

Before the early 2000s, there had been no published data on prospective clinical trials for ENKL. The low incidence of ENKL, being a relatively new lymphoma entity established in the 1990s, and complexity of its diagnosis are major general problems in conducting well-designed prospective trials for ENKL. These issues have been resolved by designing multi-institutional $[10,11]$ and/or multinational clinical trials [12-14], using diagnostic criteria according to the WHO classification, progression of the 
methodology used in lymphoma diagnosis (e.g., the availability of anti-CD56 antibodies that can be used for formalin-fixed paraffin-embedded material), and incorporating central pathology review into trials $[10,13,14]$.

Specific factors in clinical trials for localized ENKL

Two-thirds of patients have localized disease in the upper aero-digestive tract $[15,16]$, which has been referred to as nasal NKTCL [1]. Radiotherapy (RT) is believed to be a key treatment modality for this population, as the complete response (CR) rate from RT alone is $>65 \%[17,18]$. The results of several multicenter retrospective studies by radiation oncologists in East Asia suggested that a high radiation dose, radiation volume encompassing the entire nasal cavity and sinuses, and the use of CT- or magnetic resonance imaging-based radiation planning were associated with good local control [19-22]. However, most previous reports on retrospective studies of a first-line therapy including RT for localized nasal NKTCL referred only to a total dose of RT, as in studies for other lymphoma subtypes [23].

To resolve these problems, collaboration between radiation oncologists and hemato-oncologists is essential. Detailed information on radiation planning (e.g., dose prescription, schedule, definition of target volume, and instructions to prevent adverse reactions in risk organs) should be reported to facilitate the general application of the results of a study. A quality assurance program of RT $[24,25]$ is recommended to maintain the quality of RT in a prospective clinical trial for localized nasal NKTCL [26].

Specific factors in trials for disseminated ENKL

The relative incidence of advanced NKTCL among all cases of ENKL is approximately $30 \%$ [16, 27, 28]. Patients with disseminated disease often represent impaired organ function due to the disease. These factors make conducting a prospective clinical trial for this population difficult. To overcome these problems, most studies selected a setting of multinational clinical trials [12-14], although this set-up might generate some practical problems due to differences in health insurance systems in the participating countries. Some recent studies have enrolled both patients with newly diagnosed stage IV and those with relapsed or refractory disease into first-line treatment $[12,14]$.

\section{Prospective clinical trials for newly diagnosed localized nasal NKTCL}

Clinical studies initiated before the early 2000s

Anthracycline-containing chemotherapy followed by RT is established as the standard treatment for localized aggressive lymphomas, mainly diffuse large B-cell lymphomas [29]. Researchers in Samsung Medical Center in Korea conducted two single-institution clinical studies of CHOP (cyclophosphamide, doxorubicin, vincristine, and prednisone) followed by RT for stage IE or non-bulky stage IIE nasal NKTCL and reported the results [30, 31]. First, they treated 17 patients between March 1995 and December 1999. Four cycles of CHOP chemotherapy followed by involved-field RT (IF-RT) of 45 Gy were planned. The $\mathrm{CR}$ rate was $58 \%$. The planned combined modality therapy could only be completed in six patients due to early disease progression during the chemotherapy phase [30]. Next, 17 patients were treated with two cycles of dose-intensified CHOP14 (the doses of cyclophosphamide and doxorubicin were escalated to 1,250 and 75 $\mathrm{mg} / \mathrm{m}^{2}$, respectively) followed by IF-RT (44 Gy), and an additional four cycles of standard CHOP from March 2000 to June 2004. The CR rate was improved (76 \%), but five patients still experienced systemic failure. The 3-year OS was $67 \%$ [31].

These two clinical studies are praiseworthy for showing that the efficacy of CHOP chemotherapy is insufficient to treat localized nasal NKTCL, even at the maximal dose intensity. However, detailed information about the inclusion criteria, RT planning, and rationale for estimated sample size was not reported, although the researchers stated that these two studies had been conducted prospectively [11].

The ENKL tumor cells express the multidrug resistance $(M D R) 1 / A B C B 1$ gene and its product, P-glycoprotein [3234]. This observation is thought to be the major reason why ENKL is resistant to CHOP or CHOP-like chemotherapies, which are comprised mainly of MDR-related agents.

Prospective clinical trials of concurrent chemoradiotherapy for newly diagnosed localized nasal NKTCL

RT alone is insufficient to achieve a high cure rate for patients with localized nasal NKTCL due to frequent infield and systemic relapse $[17,20]$. To explore a more effective therapy for localized nasal NKTCL, prospective clinical trials of concurrent chemoradiotherapy incorporating chemotherapies with non-MDR-related agents and etoposide, which is effective against EBV-associated hemophagocytic syndrome [35], have been initiated in Japan [10] and soon after in Korea [11]. Figure 1 illustrates the protocol treatment of the two trials. The study design and results of the two clinical trials are summarized in Table 1.

The Lymphoma Study Group of the Japan Clinical Oncology Group (JCOG-LSG) began conducting a multicenter phase I/II study (JCOG0211) of concurrent chemoradiotherapy for newly diagnosed localized nasal NKTCL 
A

RT-2/3DeVIC

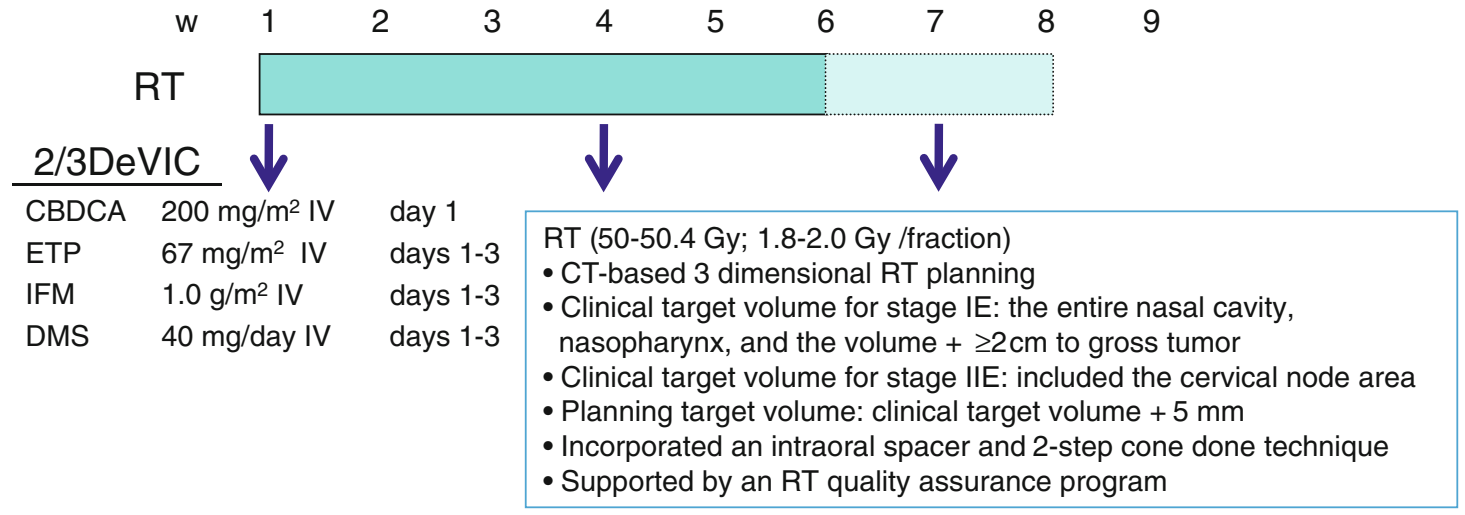

B

\section{CCRT-VIPD}
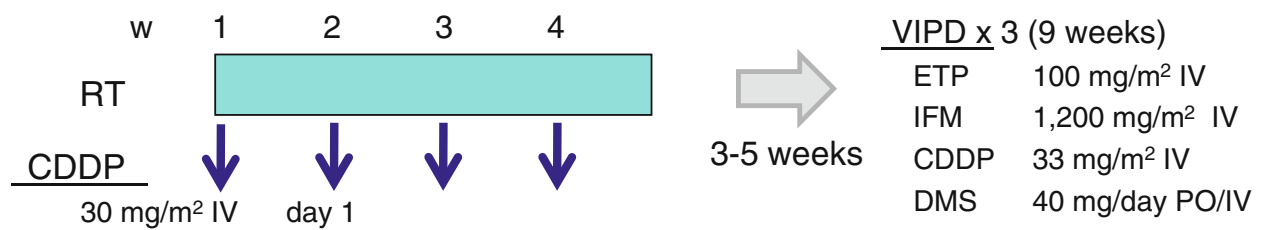

days $1-3$

days $1-3$

days 1-3

days $1-4$

RT (median dose 40 Gy; 1.8-2.0 Gy /fraction)

- CT-based 3 dimensional RT planning

- Target volume: the gross clinical lesions + adequate margins

Fig. 1 Treatment protocols in the two trials of concurrent chemoradiotherapy for untreated localized nasal NKTCL. a RT-2/3DeVIC therapy [10]; b CCRT-VIPD therapy [11]. CBDCA carboplatin,

in 2003 [10]. This study was the first prospective study for untreated localized nasal NKTCL to incorporate statistical considerations for an adequate sample size and three central reviews (i.e., a central pathology review, an RT quality assurance program [26], and a central response review). The protocol treatment comprised concurrent chemoradiotherapy with RT of 50 Gy and DeVIC (dexamethasone, etoposide, ifosfamide, carboplatin) chemotherapy [36, 37] (RT-DeVIC), which is expected to obtain both good local and systemic disease control. Patients with stage IE disease or contiguous stage IIE disease with cervical lymph node involvement were eligible for the trial. Based on the results of the phase I portion of the trial, a two-thirds dose of DeVIC (2/3DeVIC) was established as the recommended dose for the phase II portion. Twenty-seven patients who were treated with RT-2/3DeVIC were evaluated in phase II of the trial. The primary endpoint, the 2-year OS, was $78 \%$ [90\% confidence interval (CI) $61-88 \% ; 95 \%$ CI $57-89 \%$ ], which was superior to the historical control of RT alone (45\%) [17]. Acute toxicity was mild and manageable in patients treated with RT-2/3DeVIC [10]. The updated analysis of the 5-year follow-up (median follow-up
ETP etoposide, IFM ifosfamide, $D M S$ dexamethasone, $C D D P$ cisplatin, $I V$ intravenously, $P O$ orally

period 67 months; range 61-94 months) [38] revealed that the 5-year OS and progression-free survival (PFS) rates of the 27 patients treated with RT-2/3DeVIC therapy were 70 (95\% CI $49-84 \%$ ) and $63 \%$ (95\% CI $42-78 \%$ ), respectively. The analyses of toxicity confirmed that fulldose DeVIC is inappropriate due to acute and late toxicities with the concurrent use of RT in this trial.

Subsequent to the JCOG0211 trial, a Korean group (Consortium for Improving Survival of Lymphoma; CISL) initiated a multicenter phase II study of concurrent chemoradiotherapy followed by VIPD (etoposide, ifosfamide, cisplatin, and dexamethasone) chemotherapy for untreated localized nasal NKTCL in 2006 [11]. In this trial, cisplatin was selected for concurrent chemoradiotherapy as a radiation sensitizer. The median dose of RT was $40 \mathrm{~Gy}$ (range 40-52.8 Gy). Three courses of VIPD were then planned as adjuvant chemotherapy. Thirteen patients were planned to be enrolled according to their statistical considerations. The threshold value of the CR rate was estimated as $70 \%$ of RT alone [17, 39], and the expected CR rate was $90 \%$. The CR rate at the best response was $80 \%$, which was lower than the expected rate. At the median follow-up of 
Table 1 Comparison of the study design and results of two prospective clinical trials of concurrent chemoradiotherapy for localized nasal NKTCL

\begin{tabular}{|c|c|c|}
\hline & $\begin{array}{l}\text { JCOG0211 } \\
\text { study }[10,38]\end{array}$ & $\begin{array}{l}\text { CISL study } \\
\text { (CCRT-VIPD) } \\
{[11,40]}\end{array}$ \\
\hline Study design & $\begin{array}{c}\text { Multicenter, } \\
\text { phase I/II }\end{array}$ & $\begin{array}{l}\text { Multicenter, } \\
\text { phase II }\end{array}$ \\
\hline Registration period & $\begin{array}{l}\text { Sep 2003- } \\
\text { Dec } 2006\end{array}$ & $\begin{array}{l}\text { Apr 2006- } \\
\text { Oct } 2007\end{array}$ \\
\hline $\begin{array}{l}\text { Median follow-up period } \\
\text { (months, range) }\end{array}$ & $68(62-96)$ & $24(17-37)$ \\
\hline No. of patients in phase II & 27 & 30 \\
\hline $\mathrm{CR}$ rate $(\%)$ & 77 & 80 (best response) \\
\hline OS rate, \% (years) & $\begin{array}{l}78(2) \\
70(5)\end{array}$ & 86 (3; estimated) \\
\hline PFS rate, $\%$ (years) & $\begin{array}{l}67(2) \\
63(5)\end{array}$ & 80 (3; estimated) \\
\hline $\begin{array}{l}\text { Planning target volume } \\
\text { (local) control rate, } \\
\% \text { (years) }\end{array}$ & $96(2)$ & 93 (3; estimated) \\
\hline Most common toxicity & $\begin{array}{l}\text { Local } \\
\text { toxicities } \\
\text { due to RT }\end{array}$ & Infection \\
\hline
\end{tabular}

24 months (range 17-37 months), the estimated 3-year OS and PFS rates were 86 and $80 \%$, respectively [11, 40]. The estimated 3-year local control rate was $93 \%$. The toxicities during concurrent chemoradiotherapy were reported to be mild. However, grade 3 or 4 infections occurred in $60 \%$ of the patients during the VIPD therapy, and two patients died of infection. To develop a less toxic therapy than CCRT-VIPD, CISL is conducting two prospective clinical trials of modified CCRT-VIPD therapy (CCRT-VIDL [41] and CCRT-MIDLE).

Notably, both prophylactic therapies for central nervous system (CNS) relapse [42] and high-dose chemotherapy with autologous hematopoietic stem cell transplantation (HD-AHSCT) [43, 44] were not included in the protocol treatments in these two clinical trials of concurrent chemoradiotherapy.

Current recommendable management of newly diagnosed localized nasal NKTCL based on the results of prospective clinical trials

The results of the prospective clinical trials reviewed above provide important evidence as follows: (1) CHOP therapy is not effective for ENKL; (2) excellent local control can be obtained by concurrent chemoradiotherapy with nonMDR-related agents and etoposide; and (3) excellent survival data can be obtained by concurrent chemoradiotherapy without CNS prophylaxis and HD-AHSCT. Based on these data, concurrent chemoradiotherapy incorporating
Table 2 Baseline clinical characteristics of patients with localized nasal NKTCL included in two major recent retrospective studies and two prospective clinical trials of concurrent chemoradiotherapy

\begin{tabular}{|c|c|c|c|c|}
\hline \multirow{2}{*}{$\begin{array}{l}\text { Study } \\
\text { design }\end{array}$} & \multicolumn{2}{|c|}{ Retrospective study } & \multicolumn{2}{|c|}{ Prospective study } \\
\hline & $\begin{array}{l}n=82 \\
(\%)\end{array}$ & $\begin{array}{l}n=214 \\
(\%)\end{array}$ & $\begin{array}{l}n=27 \\
(\%)^{\mathrm{a}}\end{array}$ & $\begin{array}{l}n=30 \\
(\%)\end{array}$ \\
\hline Reference & $\begin{array}{l}\text { Huang } \\
\text { [47] }\end{array}$ & $\begin{array}{l}\mathrm{Li} \\
\quad[48]\end{array}$ & $\begin{array}{l}\text { JCOG0211 } \\
{[10]}\end{array}$ & $\begin{array}{l}\text { CCRT-VIPD } \\
{[11]}\end{array}$ \\
\hline Male & 70 & 66 & 63 & 57 \\
\hline \multicolumn{5}{|l|}{ Age, years } \\
\hline Median & 45 & 42 & 56 & 49 \\
\hline Range & - & $11-79$ & $21-68$ & $23-73$ \\
\hline$>60$ & $17(\geq 60)$ & 9 & 26 & 13 \\
\hline \multicolumn{5}{|l|}{ Stage } \\
\hline IE & 63 & 85 & 67 & 50 \\
\hline IIE & 37 & 15 & 33 & 50 \\
\hline \multicolumn{5}{|c|}{ B symptoms } \\
\hline Absent & 48 & 69 & 63 & 63 \\
\hline Present & 52 & 31 & 37 & 37 \\
\hline \multicolumn{5}{|c|}{ Serum LDH level } \\
\hline Normal & 62 & 66 & 81 & 80 \\
\hline Elevated & 38 & 34 & 19 & 20 \\
\hline \multicolumn{5}{|c|}{ Cervical node involvement } \\
\hline None & 85 & - & 67 & 63 \\
\hline Present & 15 & - & 33 & 37 \\
\hline \multicolumn{5}{|c|}{ Performance status (ECOG) } \\
\hline 0 or 1 & 81 & 92 & 93 & 100 \\
\hline 2 & $19(\geq 2)$ & $8(2$ or 3$)$ & 7 & 0 \\
\hline \multicolumn{5}{|l|}{ IPI score } \\
\hline 0 or 1 & 65 & - & 89 & 77 \\
\hline 2 & $35(\geq 2)$ & - & 11 & 23 \\
\hline \multicolumn{5}{|c|}{ NK-PI group } \\
\hline 1 or 2 & - & - & 63 & 70 \\
\hline 3 or 4 & - & - & 37 & 30 \\
\hline
\end{tabular}

$L D H$ lactate dehydrogenase, ECOG Eastern Cooperative Oncology Group, IPI International prognostic index, NK-PI NK/T-cell lymphoma prognostic index

a Patients who received RT-2/3DeVIC therapy

non-MDR-related agents and etoposide is recommended as a first-line treatment for localized (stage IE or contiguous stage IIE with cervical node involvement) nasal NKTCL. HD-AHSCT as a consolidative therapy after concurrent chemoradiotherapy is not recommended. Currently, RT-2/ 3DeVIC therapy is commonly used in Japan because of the short duration of the treatment (only 9 weeks to complete), experiences in the JCOG0211 trial, and the reproducibility of the radiation planning supported by a uniform protocol treatment setting and the RT quality assurance program. Its excellent efficacy in clinical practice has been recognized in Japan [45]. 
It is clear that there are patients with localized nasal NKTCL who have obtained a cure by RT alone. Because there is no publication of prospective trials on RT alone for this population, there is no firm evidence of the predictive factors that can identify these patients before treatment. A recent major retrospective study of RT alone for nasal NKTCL of stage IE excluded patients who required chemotherapy [46] suggesting the possibility of selection bias. The two prospective trials of concurrent chemoradiotherapy $[10,11]$ had not selected patients having risk factors. As shown in Table 2, the baseline clinical characteristics are comparable among the patients included in the two major recent retrospective studies of localized nasal NKTCL $[47,48]$ and those enrolled in the two prospective clinical trials of concurrent chemoradiotherapy [10, 11]. This similarity may be due to the median age at diagnosis and performance status of ENKL being lower than in other aggressive lymphomas, such as diffuse large B-cell lymphoma. A retrospective study suggested that the addition of chemotherapy to RT did not improve the clinical outcome [18]. However, evaluating the efficacy of adding chemotherapy is difficult, as CHOP or CHOP-like chemotherapies were used in the majority of patients analyzed in this study. Considering these limitations in retrospective studies and the observation that the prognosis of patients with relapsed or refractory disease after the first-line treatment remains poor, concurrent chemoradiotherapy is recommended as the current first-line treatment irrespective of the known risk factors of ENKL.

When RT-2/3DeVIC therapy is selected, performing RT following the same procedure used in the JCOG0211 study is important. If preparing for upfront RT takes considerable time (e.g., more than 1 month), chemotherapy with nonMDR-dependent agents and etoposide with sandwiched RT merits consideration [49]. However, there are no prospective data regarding the long-term efficacy of such a treatment strategy.

\section{Prospective clinical trials for newly diagnosed stage IV, relapsed or refractory ENKL}

The prognosis of patients with newly diagnosed advanced NK/T-cell lymphoma by conventional therapy is extremely poor. For example, the 1-year OS rate of patients with stage IV disease who undergo conventional treatment is $<20 \%$ [16].

Clinical trials in the early 2000 s

In 2003, two promising results of single-institution clinical studies were published. First, a Mexican group reported the results of a clinical study for newly diagnosed advanced nasal NKTCL [50]. There are no descriptions of the rationale for the planned sample size in their report. Their planned treatment comprised six cycles of CMED (cyclophosphamide, etoposide, methotrexate, and dexamethasone), with a sandwiched local RT of $55 \mathrm{~Gy}$ after the third cycle of CMED. CMED was administered every 2 weeks under G-CSF support. From 1988 to 1999, 32 patients were evaluated. With a median follow-up time of 69.1 months, both the CR rate and 5-year OS rate were $65 \%$. The researchers claimed that non-hematologic toxicity was mild in the study. CMED chemotherapy has not been regarded as a standard chemotherapeutic regimen, at least in Japan, mainly because of concerns regarding its toxicity.

The second was a clinical study by a Chinese group that evaluated the efficacy of a combined modality therapy with L-asparaginase-containing chemotherapy, also known as the Chinese regimen, for refractory NKTCL after a CHOPlike regimen [51]. According to their latest publication [52], one to six cycles of chemotherapy with L-asparaginase, vincristine, and dexamethasone followed by IF-RT at a median dose of 50 Gy (range 30-60 Gy) were planned. Forty-one patients were evaluated in the study, with no statistical consideration for the sample size being reported. The CR rate was $56 \%$. With a median follow-up period of 35 months, the 3-year OS rate was $67 \%$.

Although these two clinical studies have some limitations, such as no statistical consideration for the sample size and a single-institute setting, they suggested a promising efficacy of chemotherapy without anthracycline combined with high-dose RT. Because of its mild toxicity, the Chinese regimen is sometimes used in the current practice in Japan for elderly patients or patients with advanced disease and poor general condition.

More recently, the results of a single-institution but well-designed prospective phase II study were published [53]. In this study, 32 patients with relapsed or refractory ENKL were treated with IMVP-16/Pd (ifosfamide, methotrexate, etoposide, and prednisolone) therapy as a secondline chemotherapy from October 1996 to February 2002. All patients had received CHOP or CHOP-like chemotherapy. The overall response rate (ORR) was $44 \%$ (14/32), and the CR rate was $38 \%(12 / 32)$. Although most adverse events were mild, four patients experienced febrile neutropenia, and one died of infection. Due to its promising efficacy results, the researchers have applied this chemotherapy to patients with newly diagnosed ENKL. These results also support the efficacy of chemotherapy with non-MDR-related agents and etoposide for ENKL.

SMILE chemotherapy

To explore a more effective chemotherapeutic regimen for newly diagnosed stage IV, relapsed or refractory NKTCL, 
the NK-Cell Tumor Study Group and colleagues in East Asia designed a novel induction chemotherapy termed SMILE (steroid = dexamethasone, methotrexate, ifosfamide, L-asparaginase, etoposide) in 2004. This regimen combines non-MDR-related agents, etoposide, and L-asparaginase. Drug interactions in the sequential or concurrent administration of the four anti-cancer agents were considered. The doses of methotrexate and etoposide in SMILE were the recommended doses determined in the preceding phase I study [12].

The subsequent phase II study of SMILE was the first prospective trial for this population to incorporate an adequate sample size and two central reviews (pathology and response) [14]. Two courses of SMILE were planned as the protocol treatment. The primary endpoint was the ORR. Because the first two patients died of infection, a protocol revision adding lymphocyte count $\geq 500 / \mathrm{mm}^{3}$ to the eligibility criteria was made. No treatment-related deaths have been observed thereafter. Finally, 38 patients were evaluated in the analysis for the primary endpoint. Fiftythree percent of the patients had newly diagnosed stage IV disease. The ORR was $79 \%$ (90\% CI 65-89\%), which was clearly superior to the historical control using conventional therapy of $35 \%$. The $\mathrm{CR}$ rate was $45 \%$. In a subgroup analysis, the 1-year OS rate of the patients with newly diagnosed stage IV disease was $45 \%$ (95\% CI 23-65\%), with a median follow-up of 24 months (range 13-35 months). This 1-year OS rate was superior to the historical control of $<20 \%$ [16]. Grade 4 neutropenia was common, and the most common grade 3 or 4 non-hematologic toxicity was infection $(61 \%)$.

SMILE chemotherapy is considered the most recommendable regimen as induction chemotherapy for this population [54]. Less intensive chemotherapies based on SMILE, such as MILD (methotrexate, ifosfamide, L-asparaginase, and dexamethasone) [55] and modified SMILE [56], have been evaluated in pilot studies. MILD chemotherapy is a dose-reduced SMILE without etoposide. In modified SMILE, the seven doses of L-asparaginase in original SMILE were switched to one dose of pegylated asparaginase (pegaspargase). The preliminary results of these studies also support the efficacy of chemotherapeutic regimens containing L-asparaginase and non-MDR-related agents for ENKL.

\section{AspaMetDex therapy}

A French group conducted a multicenter phase II study of AspaMetDex (L-asparaginase, methotrexate, and dexamethasone) chemotherapy for relapsed or refractory ENKL [13]. This regimen was selected based on the promising results of their pilot study [57]. The primary endpoint of the phase II trial was a CR rate, and the planned sample size was 29. Because 11 patients out of the first 20 enrolled obtained a CR, this trial was stopped early in October 2008. Of the 19 patients evaluated, $89 \%$ had a history of $\mathrm{CHOP}$ or CHOP-like chemotherapy. The CR rate was $61 \%$, the ORR was $78 \%$, and the median survival time was 12 months.

These results clearly support the superior efficacy of L-asparaginase-containing chemotherapy for relapsed or refractory ENKL. Most patients had been treated with CHOP or CHOP-like chemotherapy before AspaMetDex in the trial, and therefore whether the AspaMetDex therapy is effective in patients who received non-anthracycline chemotherapy during the first-line therapy is unknown. Because AspaMetDex is less intensive than SMILE chemotherapy, it may be a good option for elderly patients and patients with relapsed or refractory disease with impaired organ function.

\section{Comments on HSCT for disseminated ENKL}

There are no published results of prospective clinical trials incorporating HSCT for disseminated ENKL. Several retrospective analyses have shown that some patients who underwent HSCT obtained a long-term CR [58, 59], suggesting HSCT may be a cure-oriented therapy for disseminated ENKL, although these data were obtained before 'the SMILE era'. Recently, there have been accumulating data on the promising efficacy of allogeneic HSCT for relapsed or refractory ENKL $[60,61]$, and experts in East Asia recommend allogeneic HSCT for this population [49, 62].

\section{Recommendation on the current management of ENKL based on the clinical trial results}

Figure 2 illustrates a treatment scheme for the recommended current management of ENKL based on the results of prospective clinical trials. For patients with nasal NKTCL of stage IE or contiguous stage IIE with cervical node involvement, RT-2/3DeVIC therapy is recommended as a first-line treatment. For other patients with newly diagnosed ENKL, SMILE chemotherapy is recommended as an induction therapy. Other L-asparaginase-containing chemotherapies and chemotherapies containing non-MDRrelated agents and etoposide are good candidates for patients who do not meet the eligibility criteria of the clinical trials for SMILE. The best HSCT to use after induction therapy for patients with disseminated disease remains uncertain.

The EBV DNA load in the peripheral blood has been found to be useful both for predicting the prognosis before treatment and monitoring the disease after treatment in 
Fig. 2 A treatment scheme of the recommended current management of ENKL based on the results of prospective clinical trials. There is no evidence based on prospective trials for the best management after induction therapy for patients with disseminated disease. HSCT is shown in a gray square as an option. $P R$ partial response

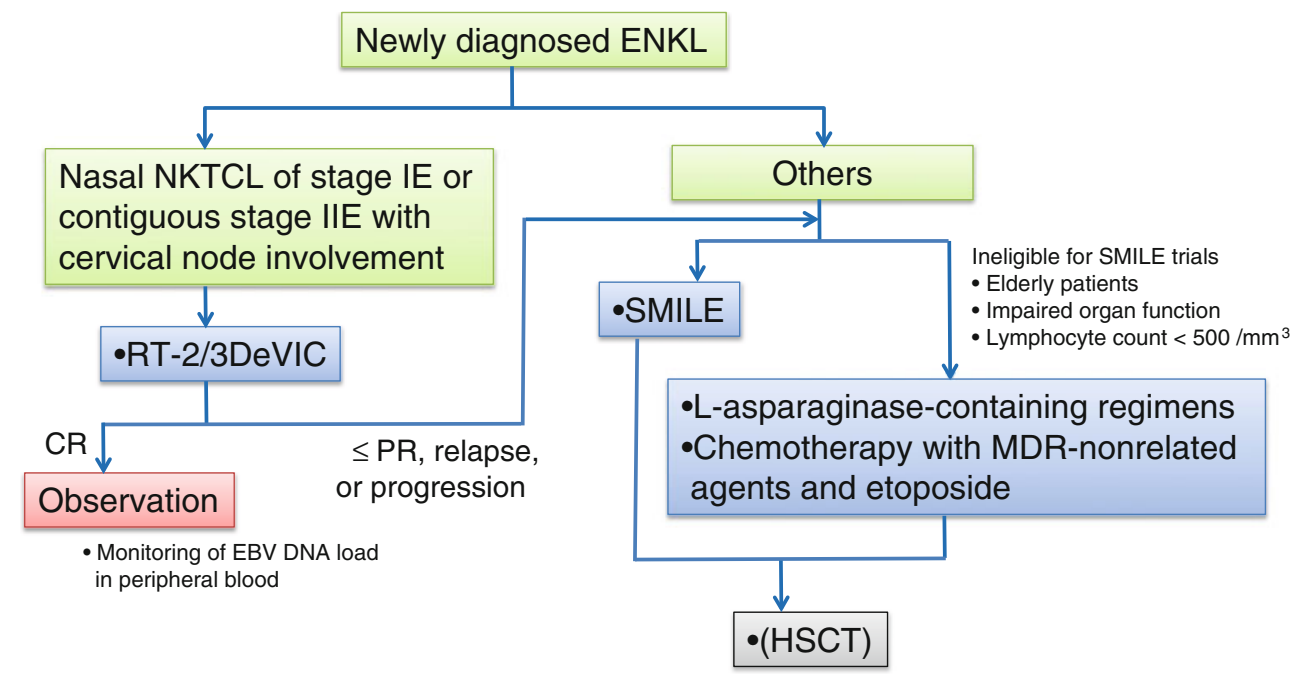

ENKL according to the results of the prospective studies and clinical trials $[11,13,63,64]$.

\section{For the better future management of ENKL}

To improve the prognosis of ENKL, identifying those patients who can obtain a cure by a treatment strategy for localized disease is important. For this purpose, strict pretreatment evaluation incorporating positron emission tomography [65-71] and in situ hybridization for EBVencoded RNA using a bone marrow specimen [72] are recommended. As chemotherapeutic regimens for ENKL are evolving, a new prognostic model among patients treated with chemotherapies without anthracycline is needed.

New RT technologies such as intensity-modulated radiation therapy deserve evaluation in prospective trials. Furthermore, the frontline use of L-asparaginase in the treatment of localized NK/T-cell lymphoma warrants evaluation. Some of the new agents for peripheral T-cell lymphomas are also expected to be effective for ENKL. Considering that $72 \%$ of ENKLs are positive for CD30 [73], one of the most promising candidates is brentuximab vedotin, i.e., the CD30-specific monoclonal antibody conjugated to an anti-tubulin agent (monomethyl auristatin E) [74]. In any case, the efficacy of a new therapeutic strategy for ENKL should be evaluated by prospective clinical trials with adequate statistical considerations, as in the cases of other aggressive lymphomas.

\section{Conclusions}

The evidence obtained from well-designed multicenter, prospective trials in the last decade contributed to improve the management of ENKL. To further improve the prognosis of patients with ENKL, well-designed prospective clinical trials need to be conducted with multidisciplinary collaborations of hemato-pathologists, radiologists, hemato-oncologists, radiation oncologists, and biostatisticians.

Acknowledgments This work was supported by the National Cancer Center Research and Development Fund [23-A-17].

Conflict of interest The author declares that there is no potential conflict of interest.

\section{References}

1. Jaffe ES, Harris NL, Stein H, Vardiman JW. World Health Organization classification of tumours. Pathology and genetics of tumours of haematopoietic and lymphoid tissues. Lyon: IARC Press; 2001.

2. Swerdlow SH, Campo E, Harris NL. WHO classification of tumours of haematopoietic and lymphoid tissues. Lyon: IARC; 2008.

3. Anderson JR, Armitage JO, Weisenburger DD. Epidemiology of the non-Hodgkin's lymphomas: distributions of the major subtypes differ by geographic locations. Non-Hodgkin's lymphoma classification project. Ann Oncol. 1998;9:717-20.

4. Vose J, Armitage J, Weisenburger D. International peripheral T-cell and natural killer/T-cell lymphoma study: pathology findings and clinical outcomes. J Clin Oncol. 2008;26:4124-30.

5. Kwong YL. Natural killer-cell malignancies: diagnosis and treatment. Leukemia. 2005;19:2186-94.

6. Oshimi K. Progress in understanding and managing natural killercell malignancies. Br J Haematol. 2007;139:532-44.

7. Liang R. Advances in the management and monitoring of extranodal NK/T-cell lymphoma, nasal type. $\mathrm{Br} \mathrm{J}$ Haematol. 2009;147:13-21.

8. Kim SJ, Kim WS. Treatment of localized extranodal NK/T cell lymphoma, nasal type. Int J Hematol. 2010;92:690-6.

9. Suzuki R. NK/T-cell lymphomas: pathobiology, prognosis and treatment paradigm. Curr Oncol Rep. 2012;14:395-402.

10. Yamaguchi M, Tobinai K, Oguchi M, Ishizuka N, Kobayashi Y, Isobe $\mathrm{Y}$, et al. Phase I/II study of concurrent chemoradiotherapy 
for localized nasal natural killer/T-cell lymphoma: Japan Clinical Oncology Group Study JCOG0211. J Clin Oncol. 2009;27:5594600.

11. Kim SJ, Kim K, Kim BS, Kim CY, Suh C, Huh J, et al. Phase II trial of concurrent radiation and weekly cisplatin followed by VIPD chemotherapy in newly diagnosed, stage IE to IIE, nasal, extranodal NK/T-cell lymphoma: consortium for improving survival of lymphoma study. J Clin Oncol. 2009;27:6027-32.

12. Yamaguchi M, Suzuki R, Kwong YL, Kim WS, Hasegawa Y, Izutsu $\mathrm{K}$, et al. Phase I study of dexamethasone, methotrexate, ifosfamide, L-asparaginase, and etoposide (SMILE) chemotherapy for advanced-stage, relapsed or refractory extranodal natural killer (NK)/T-cell lymphoma and leukemia. Cancer Sci. 2008;99:1016-20.

13. Jaccard A, Gachard N, Marin B, Rogez S, Audrain M, Suarez F, et al. Efficacy of L-asparaginase with methotrexate and dexamethasone (AspaMetDex regimen) in patients with refractory or relapsing extranodal NK/T-cell lymphoma, a phase 2 study. Blood. 2011;117:1834-9.

14. Yamaguchi M, Kwong YL, Kim WS, Maeda Y, Hashimoto C, Suh C, et al. Phase II study of SMILE chemotherapy for newly diagnosed stage IV, relapsed, or refractory extranodal natural killer (NK)/T-cell lymphoma, nasal type: the NK-Cell Tumor Study Group study. J Clin Oncol. 2011;29:4410-6.

15. Au WY, Weisenburger DD, Intragumtornchai $\mathrm{T}$, Nakamura $\mathrm{S}$, Kim WS, Sng I, et al. Clinical differences between nasal and extranasal natural killer/T-cell lymphoma: a study of 136 cases from the International Peripheral T-Cell Lymphoma Project. Blood. 2009;113:3931-7.

16. Suzuki R, Suzumiya J, Yamaguchi M, Nakamura S, Kameoka J, Kojima $\mathrm{H}$, et al. Prognostic factors for mature natural killer (NK) cell neoplasms: aggressive NK cell leukemia and extranodal NK cell lymphoma, nasal type. Ann Oncol. 2010;21:1032-40.

17. Kim GE, Cho JH, Yang WI, Chung EJ, Suh CO, Park KR, et al. Angiocentric lymphoma of the head and neck: patterns of systemic failure after radiation treatment. J Clin Oncol. 2000;18:54-63.

18. Li YX, Yao B, Jin J, Wang WH, Liu YP, Song YW, et al. Radiotherapy as primary treatment for stage IE and IIE nasal natural killer/T-cell lymphoma. J Clin Oncol. 2006;24:181-9.

19. Shikama N, Ikeda H, Nakamura S, Oguchi M, Isobe K, Hirota S, et al. Localized aggressive non-Hodgkin's lymphoma of the nasal cavity: a survey by the Japan Lymphoma Radiation Therapy Group. Int J Radiat Oncol Biol Phys. 2001;51:1228-33.

20. Cheung MM, Chan JK, Lau WH, Ngan RK, Foo WW. Early stage nasal NK/T-cell lymphoma: clinical outcome, prognostic factors, and the effect of treatment modality. Int $\mathbf{J}$ Radiat Oncol Biol Phys. 2002;54:182-90.

21. Koom WS, Chung EJ, Yang WI, Shim SJ, Suh CO, Roh JK, et al. Angiocentric T-cell and NK/T-cell lymphomas: radiotherapeutic viewpoints. Int J Radiat Oncol Biol Phys. 2004;59:1127-37.

22. Isobe K, Uno T, Tamaru J, Kawakami H, Ueno N, Wakita H, et al. Extranodal natural killer/T-cell lymphoma, nasal type: the significance of radiotherapeutic parameters. Cancer. 2006;106:609-15.

23. Bekelman JE, Yahalom J. Quality of radiotherapy reporting in randomized controlled trials of Hodgkin's lymphoma and nonHodgkin's lymphoma: a systematic review. Int J Radiat Oncol Biol Phys. 2009;73:492-8.

24. Eich HT, Engenhart-Cabillic R, Hansemann K, Lukas P, Schneeweiss A, Seegenschmiedt $\mathrm{H}$, et al. Quality control of involved field radiotherapy in patients with early-favorable (HD10) and early-unfavorable (HD11) Hodgkin's lymphoma: an analysis of the German Hodgkin Study Group. Int J Radiat Oncol Biol Phys. 2008;71:1419-24.

25. Sanuki N, Ishikura S, Shinoda M, Ito Y, Hayakawa K, Ando N. Radiotherapy quality assurance review for a multi-center randomized trial of locally advanced esophageal cancer: the Japan
Clinical Oncology Group (JCOG) trial 0303. Int J Clin Oncol. 2012;17:105-11.

26. Oguchi M, Kagami Y, Ishikura S, Nihei K, Ito Y, Yamaguchi M, et al. Upfront radiotherapy with concurrent chemotherapy for localized nasal NK/T-cell lymphoma: radiotherapy quality assurance (QA) review in Japan Clinical Oncology Group (JCOG) Trial 0211. Int J Radiat Oncol Biol Phys. 2008 (abstr 2682);72:S474.

27. Lee J, Suh C, Park YH, Ko YH, Bang SM, Lee JH, et al. Extranodal natural killer T-cell lymphoma, nasal-type: a prognostic model from a retrospective multicenter study. J Clin Oncol. 2006;24:612-8.

28. Kim TM, Lee SY, Jeon YK, Ryoo BY, Cho GJ, Hong YS, et al. Clinical heterogeneity of extranodal NK/T-cell lymphoma, nasal type: a national survey of the Korean Cancer Study Group. Ann Oncol. 2008;19:1477-84.

29. Miller TP, Dahlberg S, Cassady JR, Adelstein DJ, Spier CM, Grogan TM, et al. Chemotherapy alone compared with chemotherapy plus radiotherapy for localized intermediate- and highgrade non-Hodgkin's lymphoma. N Engl J Med. 1998;339:21-6.

30. Kim WS, Song SY, Ahn YC, Ko YH, Baek CH, Kim DY, et al. CHOP followed by involved field radiation: is it optimal for localized nasal natural killer/T-cell lymphoma? Ann Oncol. 2001;12:349-52.

31. Lee SH, Ahn YC, Kim WS, Ko YH, Kim K, Park K. The effect of pre-irradiation dose intense $\mathrm{CHOP}$ on anthracycline resistance in localized nasal NK/T-cell lymphoma. Haematologica. 2006;91: 427-8.

32. Yamaguchi M, Kita K, Miwa H, Nishii K, Oka K, Ohno T, et al. Frequent expression of P-glycoprotein/MDR1 by nasal T-cell lymphoma cells. Cancer. 1995;76:2351-6.

33. Drenou B, Lamy T, Amiot L, Fardel O, Caulet-Maugendre S, Sasportes M, et al. CD3- CD56+ non-Hodgkin's lymphomas with an aggressive behavior related to multidrug resistance. Blood. 1997;89:2966-74.

34. Egashira M, Kawamata N, Sugimoto K, Kaneko T, Oshimi K. P-glycoprotein expression on normal and abnormally expanded natural killer cells and inhibition of P-glycoprotein function by cyclosporin A and its analogue, PSC833. Blood. 1999;93:599-606.

35. Imashuku S, Kuriyama K, Teramura T, Ishii E, Kinugawa N, Kato $\mathrm{M}$, et al. Requirement for etoposide in the treatment of Epstein-Barr virus-associated hemophagocytic lymphohistiocytosis. J Clin Oncol. 2001;19:2665-73.

36. Okamoto M, Maruyama F, Tsuzuki M, Nomura T, Miyazaki H, Wakita M, et al. Salvage chemotherapy for relapsed/refractory aggressive non-Hodgkin's lymphoma with a combination of dexamethasone, etoposide, ifosfamide and carboplatin. Rinsho Ketsueki. 1994;35:635-41.

37. Yamaguchi M, Ogawa S, Nomoto Y, Oka K, Taniguchi M, Nakase K, et al. Treatment outcome of nasal NK-cell lymphoma: a report of 12 consecutively-diagnosed cases and a review of the literature. J Clin Exp Hematop. 2001;41:93-9.

38. Yamaguchi M, Tobinai K, Oguchi M, Ishizuka N, Kobayashi Y, Isobe $\mathrm{Y}$, et al. Concurrent chemoradiotherapy for localized nasal natural killer/T-cell lymphoma: an updated analysis of the Japan Clinical Oncology Group study JCOG0211. J Clin Oncol. 2012. doi: 10.1200/JCO.2012.45.6541.

39. You JY, Chi KH, Yang MH, Chen CC, Ho CH, Chau WK, et al. Radiation therapy versus chemotherapy as initial treatment for localized nasal natural killer (NK)/T-cell lymphoma: a single institute survey in Taiwan. Ann Oncol. 2004;15:618-25.

40. Shimada K, Suzuki R. Concurrent chemoradiotherapy for limited-stage extranodal natural killer/T-cell lymphoma, nasal type. J Clin Oncol. 2010;28:e229 (author reply e230).

41. Kim SJ, Eom HS, Kim JS, Kwak JY, Yang DH, Park SK, et al. Concurrent chemo-radiotherapy followed by VIDL (etoposide, 
ifosfamide, dexamethasone, L-asparaginase) chemotherapy in stage I/II extranodal NK/T-cell lymphoma of nasal cavity/nasopharynx. ASH Annu Meet Abstr. 2010;2010:116.

42. Kim SJ, Oh SY, Hong JY, Chang MH, Lee DH, Huh J, et al. When do we need central nervous system prophylaxis in patients with extranodal NK/T-cell lymphoma, nasal type? Ann Oncol. 2010;21:1058-63.

43. Kim SJ, Kim BS, Choi CW, Seo HY, Seol HR, Sung HJ, et al. Treatment outcome of front-line systemic chemotherapy for localized extranodal NK/T cell lymphoma in nasal and upper aerodigestive tract. Leuk Lymphoma. 2006;47:1265-73.

44. Lee J, Au WY, Park MJ, Suzumiya J, Nakamura S, Kameoka J, et al. Autologous hematopoietic stem cell transplantation in extranodal natural killer/T cell lymphoma: a multinational, multicenter, matched controlled study. Biol Blood Marrow Transpl. 2008;14:1356-64.

45. Hyo R, Ishida F, Isobe $K$, Izutsu $K$, Kimura $H$, Kawa $K$, et al. Improved prognosis of NK-cell lymphoma/leukemia, but not for T-cell lymphomas: a nationwide survey of NK- and associated T-cell neoplasms by the NK-Cell Tumor Study Group (NKTSG). Ann Oncol. 2011;22(suppl 4):iv164.

46. Li YX, Wang H, Jin J, Wang WH, Liu QF, Song YW, et al. Radiotherapy alone with curative intent in patients with stage I extranodal nasal-type NK/T-cell lymphoma. Int J Radiat Oncol Biol Phys. 2012;82:1809-15.

47. Huang MJ, Jiang Y, Liu WP, Li ZP, Li M, Zhou L, et al. Early or up-front radiotherapy improved survival of localized extranodal NK/T-cell lymphoma, nasal-type in the upper aerodigestive tract. Int J Radiat Oncol Biol Phys. 2008;70:166-74.

48. Li YX, Liu QF, Wang WH, Jin J, Song YW, Wang SL, et al. Failure patterns and clinical implications in early stage nasal natural killer/T-cell lymphoma treated with primary radiotherapy. Cancer. 2011;117:5203-11.

49. Kwong YL, Anderson BO, Advani R, Kim WS, Levine AM, Lim ST. Management of T-cell and natural-killer-cell neoplasms in Asia: consensus statement from the Asian Oncology Summit 2009. Lancet Oncol. 2009;10:1093-101.

50. Aviles A, Neri N, Fernandez R, Calva A, Huerta-Guzman J, Nambo MJ. Nasal NK/T-cell lymphoma with disseminated disease treated with aggressive combined therapy. Med Oncol. 2003;20:13-7.

51. Yong W, Zheng W, Zhang Y, Zhu J, Wei Y, Zhu D, et al. L-asparaginase-based regimen in the treatment of refractory midline nasal/nasal-type T/NK-cell lymphoma. Int J Hematol. 2003;78:163-7.

52. Yong W, Zheng W, Zhu J, Zhang Y, Wang X, Xie Y, et al. LAsparaginase in the treatment of refractory and relapsed extranodal NK/T-cell lymphoma, nasal type. Ann Hematol. 2009;88: 647-52.

53. Kim BS, Kim DW, Im SA, Kim CW, Kim TY, Yoon SS, et al. Effective second-line chemotherapy for extranodal NK/T-cell lymphoma consisting of etoposide, ifosfamide, methotrexate, and prednisolone. Ann Oncol. 2009;20:121-8.

54. Armitage JO. The aggressive peripheral T-cell lymphomas: 2012 update on diagnosis, risk stratification, and management. Am J Hematol. 2012;87:511-9.

55. Tsukune Y, Isobe Y, Yasuda H, Shimizu S, Katsuoka Y, Hosone $\mathrm{M}$, et al. Activity and safety of combination chemotherapy with methotrexate, ifosfamide, L-asparaginase and dexamethasone (MILD) for refractory lymphoid malignancies: a pilot study. Eur J Haematol. 2010;84:310-5.

56. Lunning MA, Pamer E, Wintman L, Bhatt V, Yahalom J, Moskowitz AJ, et al. Modified SMILE in the treatment of natural killer T-cell lymphoma, nasal and nasal type: a single center US experience. ASH Annu Meet Abstr. 2011;118:2688.
57. Jaccard A, Petit B, Girault S, Suarez F, Gressin R, Zini JM, et al. L-Asparaginase-based treatment of 15 western patients with extranodal NK/T-cell lymphoma and leukemia and a review of the literature. Ann Oncol. 2009;20:110-6.

58. Murashige N, Kami M, Kishi Y, Kim SW, Takeuchi M, Matsue $\mathrm{K}$, et al. Allogeneic haematopoietic stem cell transplantation as a promising treatment for natural killer-cell neoplasms. Br J Haematol. 2005;130:561-7.

59. Suzuki R, Suzumiya J, Nakamura S, Kagami Y, Kameoka JI, Sakai C, et al. Hematopoietic stem cell transplantation for natural killer-cell lineage neoplasms. Bone Marrow Transpl. 2006;37: 425-31.

60. Yokoyama H, Yamamoto J, Tohmiya Y, Yamada MF, Ohguchi $\mathrm{H}$, Ohnishi $\mathrm{Y}$, et al. Allogeneic hematopoietic stem cell transplant following chemotherapy containing L-asparaginase as a promising treatment for patients with relapsed or refractory extranodal natural killer/T cell lymphoma, nasal type. Leuk Lymphoma. 2010;51:1509-12.

61. Li M, Gao C, Li H, Wang Z, Cao Y, Huang W, et al. Allogeneic haematopoietic stem cell transplantation as a salvage strategy for relapsed or refractory nasal NK/T-cell lymphoma. Med Oncol. 2011;28:840-5.

62. Suzuki R. Treatment of advanced extranodal NK/T cell lymphoma, nasal-type and aggressive NK-cell leukemia. Int $\mathbf{J}$ Hematol. 2010;92:697-701.

63. Suzuki R, Yamaguchi M, Izutsu K, Yamamoto G, Takada K, Harabuchi Y, et al. Prospective measurement of Epstein-Barr virus-DNA in plasma and peripheral blood mononuclear cells of extranodal NK/T-cell lymphoma, nasal type. Blood. 2011;118: 6018-22.

64. Ito $\mathrm{Y}$, Kimura $\mathrm{H}$, Maeda $\mathrm{Y}$, Hashimoto $\mathrm{C}$, Ishida $\mathrm{F}$, Izutsu $\mathrm{K}$, et al. Pretreatment EBV-DNA copy number is predictive of response and toxicities to SMILE chemotherapy for extranodal NK/T-cell lymphoma, nasal type. Clin Cancer Res. 2012;18: 4183-90.

65. Tsukamoto N, Kojima M, Hasegawa M, Oriuchi N, Matsushima T, Yokohama A, et al. The usefulness of (18)F-fluorodeoxyglucose positron emission tomography ((18)F-FDG-PET) and a comparison of (18)F-FDG-pet with (67)gallium scintigraphy in the evaluation of lymphoma: relation to histologic subtypes based on the World Health Organization classification. Cancer. 2007; 110:652-9.

66. Kako S, Izutsu K, Ota Y, Minatani Y, Sugaya M, Momose T, et al. FDG-PET in T-cell and NK-cell neoplasms. Ann Oncol. 2007;18:1685-90.

67. Karantanis D, Subramaniam RM, Peller PJ, Lowe VJ, Durski JM, Collins DA, et al. The value of [(18)F]fluorodeoxyglucose positron emission tomography/computed tomography in extranodal natural killer/T-cell lymphoma. Clin Lymphoma Myeloma. 2008;8:94-9.

68. Khong PL, Pang CB, Liang R, Kwong YL, Au WY. Fluorine-18 fluorodeoxyglucose positron emission tomography in mature T-cell and natural killer cell malignancies. Ann Hematol. 2008;87:613-21.

69. Suh C, Kang YK, Roh JL, Kim MR, Kim JS, Huh J, et al. Prognostic value of tumor 18F-FDG uptake in patients with untreated extranodal natural killer/T-cell lymphomas of the head and neck. J Nucl Med. 2008;49:1783-9.

70. Cahu X, Bodet-Milin C, Brissot E, Maisonneuve H, Houot R, Morineau N, et al. 18F-fluorodeoxyglucose-positron emission tomography before, during and after treatment in mature $\mathrm{T} / \mathrm{NK}$ lymphomas: a study from the GOELAMS group. Ann Oncol. 2011;22:705-11.

71. Fujiwara H, Maeda Y, Nawa Y, Yamakura M, Ennishi D, Miyazaki Y, et al. The utility of positron emission tomography/ 
computed tomography in the staging of extranodal natural killer/ T-cell lymphoma. Eur J Haematol. 2011;87:123-9.

72. Lee J, Suh C, Huh J, Jun HJ, Kim K, Jung C, et al. Effect of positive bone marrow EBV in situ hybridization in staging and survival of localized extranodal natural killer/T-cell lymphoma, nasal-type. Clin Cancer Res. 2007;13:3250-4.

73. Pongpruttipan T, Sukpanichnant S, Assanasen T, Wannakrairot $P$, Boonsakan P, Kanoksil W, et al. Extranodal NK/T-cell lymphoma, nasal type, includes cases of natural killer cell and alphabeta, gammadelta, and alphabeta/gammadelta T-cell origin: a comprehensive clinicopathologic and phenotypic study. Am J Surg Pathol. 2012;36:481-99.

74. Younes A, Bartlett NL, Leonard JP, Kennedy DA, Lynch CM, Sievers EL, et al. Brentuximab vedotin (SGN-35) for relapsed CD30-positive lymphomas. N Engl J Med. 2010;363:1812-21. 